\title{
Projeto Rondon: uma lição de cidadania extensão
}

\author{
Rondon project: a lesson extension of citizenship \\ Leonardo Casimiro' \\ 'Universidade Católica Dom Bosco (UCDB) - MS - Brasil
}

\begin{abstract}
Resumo
A Extensão Universitária é um processo educativo, cultural e científico que articula o Ensino e a Pesquisa de forma indissociável e viabiliza a relação transformadora entre Universidade e Sociedade garantindo aos estudantes a oportunidade de elaboração da práxis de um conhecimento acadêmico, pois no retorno à Universidade, os acadêmicos trazem um aprendizado que é acumulado àquele conhecimento. Este trabalho relata a experiência vivida durante as férias universitárias pelos acadêmicos do curso de agronomia da Universidade Católica Dom Bosco (UCDB) na participação do Projeto Rondon, operação "Portal da Amazônia" realizada em Tocantinópolis - TO, no período de 25 de janeiro a 10 de fevereiro de 2014. Neste período os acadêmicos rondonistas realizaram oficinas abordando o tema: Produção de hortas comunitárias. Serão expressos os impactos verificados e contribuições deixadas pelo Projeto Rondon durante sua ação, com foco nas atividades realizadas pelos rondonistas. Apresenta uma abordagem da história do Projeto Rondon e de Marechal Candido da Silva Rondon como foram criados os princípios vivenciados por ele e o que propôs à sociedade brasileira e ao mundo. Para elaboração deste relato de experiência foram utilizados dados, documentos e fotos, colhidos nas capacitações realizadas.
\end{abstract}

Palavras-chave: Conhecimento, Cidadania, Educação, Extensão Universitária, Formação profissional, Projeto Rondon.

\begin{abstract}
The University Extension is an educational, cultural and scientific process that articulates the Teaching and Research inseparably and enables the transforming relationship between University and Society guaranteeing students the opportunity of developing the praxis of a scholarship, because the return to the University, bring academic learning that is accumulated that knowledge. This paper reports the experience during university vacations for students of agronomy at Dom Bosco Catholic University (UCDB) participation in the Project Rondon, operation 'Amazon Portal "held in Tocantinópolis - TO, the period of January 25 to 10 February 2014 in this period the academic rondonistas held workshops addressing the theme: Production of community gardens. The observed impacts and contributions left by Rondon Project during its action, focusing on the activities carried out by rondonistas be expressed. Presents an approach to the history of the Rondon Project and Marechal Candido da Silva Rondon and the principles he lived by were created and what they proposed to the Brazilian society and the world. Used data, documents and photographs, collected in the training conducted to prepare this experience report.
\end{abstract}

Keywords: Knowledge, Citizenship, Education, Continuing Education, Training, Rondon Project. 


\section{INTRODUÇÃO}

Segundo Barreto (2008), quando se fala em Rondon, fala-se em ações e práticas que se afirmam em preparação às comunidades e são desenvolvidas pelos universitários com seus professores, possibilitando-os a se qualificarem no saber acadêmico, conhecer e vivenciar a realidade brasileira, construindo linhas de ações e abrindo caminhos para se inserir como uma missão que integra e fascina o universitário-cidadão.

E o Projeto tem como filosofia motivar o jovem universitário e professores a saírem do casulo de suas famílias, dos seus bairros, cidades e estados e se envolverem com a realidade brasileira (BARRETO, 2008).

Este trabalho apresenta a experiência vivenciada pelos acadêmicos de Agronomia, autores deste trabalho, no Projeto Rondon, operação "Portal da Amazônia" realizado no município de Tocantinópolis - TO. O projeto encontra-se inserido nas ações extensionistas desenvolvidas pela Universidade Católica Dom Bosco (UCDB) de Campo Grande - Mato Grosso do Sul. O presente trabalho tem por objetivo apresentar as atividades desenvolvidas no Projeto Rondon com a temática de "Produção de hortas comunitárias" realizado pelos rondonistas em sua participação no projeto nas férias de janeiro/ fevereiro do ano de 2014.

Para sua elaboração foram utilizados dados colhidos durante a experiência no projeto. É necessário compreender a trajetória do projeto para se ter noção da importância do Projeto Rondon na extensão e também um breve histórico seu na contribuição da formação do universitário como cidadão. A temática aborda uma característica técnica para as atividades do projeto, uma vez que o trabalho tem como objetivo descrever as ações realizadas pelos rondonistas durante suas capacitações, buscando avaliar a contribuição e a troca de experiência entre as pessoas que participaram das capacitações.

\section{DESENVOLVIMENTO}

O Projeto Rondon foi idealizado pelo professor Wilson Choeri da antiga Universidade de Estado da Guanabara (UEG), atualmente Universidade Estadual do Rio de Janeiro. O nome foi inspirado na figura do bandeirante e pioneiro da integração nacional Marechal Candido da Silva Rondon (BARRETO, 2008). Rondon abriu caminhos, desbravando terras, lançando linhas telegráficas, fazendo mapeamentos do terreno e principalmente estabelecendo relações cordiais com os índios (BRASIL, 2008).

Criado em 11 de julho de 1967, durante a ditadura militar, o Projeto Rondon tinha como lema "integrar para não entregar", expressando um ideário desenvolvimentista articulado à doutrina de segurança nacional. O projeto promovia atividades de extensão universitária levando estudantes voluntários às comunidades carentes e isoladas do interior do país, onde participavam de atividades de caráter notadamente assistencial, organizadas pelo governo (BRASIL, 2008). A idéia surgiu em 1966, na Escola de Comando e Estado-Maior do Exército, durante a realização de um trabalho de sociologia intitulado "O Militar e a Sociedade Brasileira". A primeira operação do Projeto Rondon, denominada "Operação Zero", teve início em 11 de julho de 1967, quando trinta estudantes e dois professores partiram do Rio de Janeiro para Rondônia, a bordo de uma aeronave $\underline{C}-47$, cedida pelo antigo Ministério do Interior, com a equipe permanecendo na área por 28 dias, realizando trabalhos de levantamento, pesquisa e assistência médica. O Projeto Rondon foi retomado pelo governo fede-

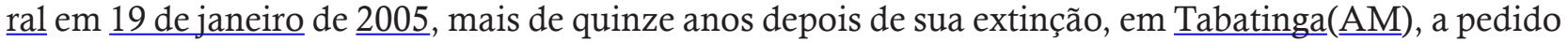
da União Nacional dos Estudantes (UNE). O Projeto Rondon é um projeto de integração social que envolve a participação voluntária de estudantes universitários na busca de soluções que contribuam para o desenvolvimento sustentável de comunidades carentes e ampliem o bem-estar da população, tendo como objetivo a contribuição na formação do universitário como cidadão, buscando Integrar o universitário ao processo de desenvolvimento nacional, por meio de ações participativas sobre a realidade do País. Uma operação do Projeto Rondon segue as etapas que vão desde planejamento até a formulação de um relatório final. O planejamento realizado pelo Projeto Rondon se inicia com a definição da região e dos estados onde a operação será realizada. Assim é feito um levantamento dos municípios de interesse da área (baixo IDH, tamanho do município etc.) e detalhamento das necessidades logísticas. A primeira etapa ocorre quando os municípios selecionados recebem a visita de um integrante do projeto para informar à prefeitura e às lideranças locais sobre as possibilidades e as 
limitações do trabalho dos rondonistas, verificam também se os conjuntos de ações selecionadas para a operação respondem às principais necessidades do município e carências da população, nesta fase a prefeitura confirma seu interesse em aderir e participar do Projeto Rondon. Após a divulgação das IES selecionadas, os professores que coordenarão as equipes de rondonistas visitam os municípios e ajustam com as lideranças municipais e as prefeituras as ações que serão realizadas pela universidade durante a operação, de forma a atender às reais necessidades de cada município. Neste momento também é definido o apoio logístico (alojamento, alimentação e transporte no interior do município) que será prestado aos rondonistas. A equipe é composta por dois professores e oito alunos, após a definição da equipe foram realizadas capacitações sobre a temática. Cada equipe deve ser multidisciplinar, de forma a possibilitar a realização das diversas ações previstas. A operação teve a duração de 15 dias, sendo os dois primeiros destinados à concentração, ambientação, abertura e deslocamento dos rondonistas aos municípios e o último para o encerramento e retorno às cidades de origem. Ao término de todas as atividades a IES envia o relatório dos trabalhos desenvolvidos no município. A proposta do Projeto Rondon é consolidar no universitário brasileiro o sentido de responsabilidade social, coletiva, em prol da cidadania, do desenvolvimento e da defesa dos interesses nacionais. Estimular no universitário a produção de projetos coletivos locais, em parceria com as comunidades assistidas (BRASIL, 2008).

A extensão universitária é o lócus para uma vivência universitária, a importância da prática da extensão se encontra na construção de um caráter crítico que incita à mobilização no sentido de transformar a realidade em que se vive. Sendo assim, o projeto Rondon é uma forma de produzir e difundir conhecimentos aspirando mudanças que contribuam para a transformação social, não só no âmbito do município que recebe a intervenção, mas nos futuros campos de atuação do aluno e futuro profissional (ABRANCHES; MELO; ÁVILA, 2009). Tal construção de conhecimentos e experiências acontece através de uma rede de interdisciplinaridade.

As discussões sobre o fortalecimento da extensão dentro das universidades brasileiras não são novas. BRASIL (2007), em uma análise da institucionalização da extensão universitária pública brasileira, buscou delinear a concepção de extensão universitária brasileira, a função prioritária da extensão nas universidades, as formas de operacionalização das ações de extensão, as instâncias responsáveis pela política e execução da extensão universitária, bem como as dificuldades para o desenvolvimento da extensão universitária brasileira.

$\mathrm{Na}$ ação desenvolvida no Projeto Rondon pela UCDB e pelos rondonistas no município de Tocantinópolis-TO, a horta constitui-se importante modalidade de produção e consumo da população considerando o ponto de vista nutricional, como forma de terapia ocupacional, na melhoria do hábito de consumo das pessoas, na economia das famílias e até na manutenção e/ou melhoria da saúde e prevenção de doenças. O fato é que além de ser saudável para o cultivo de plantas é também uma 'terapia verde', pois o contato com a terra, sementes, folhas e o acompanhamento de todo o desenvolvimento da planta leva o indivíduo a fazer parte de algo maior, que tem vida, alegra e alimenta.

As hortas nas escolas podem se tornar um fator de conscientização e motivação dos alunos e da comunidade para a realização de refeições mais saudáveis em vista possibilidade de participação ativa nos processos de produção, colheita e preparo dos alimentos. A participação de alunos, professores e funcionários na implantação da horta é de suma importância para que haja uma integração entre diferentes fontes de informação, permitindo assim uma maior troca de experiências.

\section{METODOLOGIA}

Os rondonistas autores deste trabalho desenvolveram capacitações abordando a construção e manutenção de hortas, a metodologia proposta constituiu-se em oficinas, palestras e visitas a propriedades rurais. Os rondonistas atenderam a vários públicos, como crianças, produtores, idoso, além de oficinas realizadas em aldeias.

"Dizer não para o Projeto Rondon é dizer não para o desenvolvimento"

(Edilson Bezerra, Secretário da Juventude e Política contra drogas na abertura do evento - 2014).

Assim se deu inicio as atividades do Projeto Rondon na cidade de Tocantinópolis, com esta 
frase que retrata o sentimento de todos da cidade no momento de abertura do projeto. Na primeira oficina realizada pelos acadêmicos intitulada "Produção de Horta Comunitária", totalizando aproximadamente 15 pessoas, dentre os participantes sua maioria produtores, a oficina foi realizada na Secretária de juventude e política contras as drogas a pedido do secretário Edilson Bezerra, já que menores infratores pagam pena no local, a oficina tinha como objetivo capacitar os jovens para que dessem continuidade na horta levantada pelos acadêmicos. O levantamento dessa horta teve início com a limpeza do terreno pelos rondonistas, levantamento dos canteiros, com auxílio da comunidade, após isso foi aplicado uma palestra dando ênfase na produção e manutenção de hortas, detalhando o passo a passo desde o levantamento do canteiro até a colheita das culturas, após o término da palestra deu se inicio as atividades práticas, iniciando-se pela produção do substrato, assim como a proporção a ser utilizado no levantamento do canteiro, utilizando-se matéria-prima local, como a casca do fruto do babaçu (fruto típico da região), em seguida foi realizado a semeadura pelos próprios participantes que escolheram quais culturas a serem plantadas, e em seguida finalizando a atividade foi feita a irrigação. Nessa atividade destacou-se o interesse dos produtores na oficina, os rondonistas relatam o quanto foi gratificante ver o interesse e o respeito que os participantes tinham com cada palavra dita, estavam ali atentos para novos conhecimentos. No momento em que se dava o levantamento do canteiro da horta, os rondonistas ouviram de um dos participantes: "Era bem assim que eu ajudava a minha mãe há uns anos atrás". Essa declaração trouxe à tona que, por mais simples que pode ser um trabalho, ele carrega um enorme valor e respeito para qualquer pessoa, ressurgindo ali naquele momento valores passados de geração anteriores.

No mesmo dia os rondonista visitaram uma propriedade particular onde fizeram recomendações de adubações em canteiros e pomares, em função de deficiências nutricionais. Ainda no mesmo dia, os rondonistas foram chamados para verificarem o gramado do campo de futebol municipal que apresentou ataques de uma lagarta, os rondonistas identificaram a lagarta do gênero helicoverpa e recomendaram um inseticida para o controle da praga.

Duas experiências que não podem deixar de serem citadas neste trabalho foi a visita dos rondonistas as aldeias ao entorno do município. Os rondonistas visitaram duas aldeias, a Aldeia Indígena Apinajé "Mariazinha", e a Aldeia Indígena Apinajé "São José", realizaram capacitações prática e palestras teóricas sobre produção de horta pra mais de 80 pessoas, dentre crianças de 5 a 8 anos de idade e adultos. Os índios participantes das oficinas após todo conhecimento prático/teórico aplicado pelos rondonistas, escolheram as culturas a serem semeadas no canteiro, e foi interessante ver o interesse deles na atividade, mesmo não sendo hábito indígena o cultivo de hortaliças, após a realização da semeadura as crianças produziram placas identificando as hortaliças plantadas na linguagem deles o apinajé (linguagem oficial da comunidade), já que crianças até 6 anos de idade não falam português. $\mathrm{O}$ mais marcante na visita dos rondonistas as aldeias foi quando um índio se aproximou dos rondonistas durante a atividade da produção de horta, ficou ali observando atentamente os rondonistas no levantamento dos canteiros, logo começou a dialogar com os rondonistas dizendo que gostaria que o projeto fosse desenvolvido na aldeia e que tinha muita vontade de participar, em seguida se aproximou um pouco mais pedindo para tirar uma foto com os rondonistas e em seguida disse:

"Onde posso revelar essa foto, pois quero fazer um quadro!"

(Márcio, índio apinajé da Aldeia "São José".)

Outro fato marcante durante a visita foi o batizado de um dos rondonistas:

"São poucas pessoas que eu me simpatizo, e quando isso acontece eu gosto de apadrinhar."

Disse o cacique Orlando quando ele levava "agora o seu afilhado" um dos rondonistas para sua casa conhecer a sua família, o rondonista foi batizado com o nome indígena apinajé Atorhkrã, que em português significa homem grande.

O sucesso das atividades se estendeu nas escola da rede municipal de ensino do município, onde os rondonistas realizaram capacitações em três escolas de ensino primário, aproximadamente cerca de 80 crianças dentre o 1o e 4o ano participaram da atividade de "Construção de Horta", os rondonistas demonstraram mais uma vez todo o processo desde a preparação do solo, semeadura até a irrigação, destacando também a importância da qualidade de um alimento e um hábito saudável que é o cultivo de uma horta, focaram também na capacitação dos multiplicadores, no caso os professores, que também receberam instruções de como trabalhar com as crianças atividades pedagógicas ligadas a horta. Em algumas vezes o local destinado para a construção da horta não era o adequado, faltava estrutura desde matérias simples como regador ou pela alta compactação do solo, mais os rondonistas 
com espírito desbravadores cujo nome do projeto faz sentido, não desanimaram em momento algum e fizeram das dificuldades obstáculos de crescimento pessoal, fizeram o possível para o levantamento dos canteiros, retiravam solo de outro local para o levantamento do canteiro, reaproveitamento de garrafas pets para cercar a horta e também fazer regador. Após todos os passos para o levantamento do canteiro as crianças realizaram a semeadura e a irrigação do canteiro, com instrução dos rondonistas, era visível a felicidade das crianças em se sentir útil, estar ali plantando seu próprio alimento, ótimo exercício físico além de representar uma forma de aprendizado saudável e criativo, tal qual o contato com as coisas da natureza, despertando o interesse das crianças no cuidado com o meio-ambiente.

E finalizando as atividades nos últimos dias, os rondonistas realizaram atividades no CRAS Centro de reabilitação e assistência social, nesse local já havia um grupo de idosos que sempre se reunia para a realização de atividades, essa oficina não estava prevista, mais devida ao pedido irrecusável da coordenadora do local senhora Maria da Consolação, que foi até onde estava hospedada a equipe do Projeto Rondon pedir pessoalmente a capacitação ao saber do sucesso das oficinas, os rondonistas arrumaram tempo e realizaram a última oficina de "Construção de Horta" com os idosos. Os rondonistas realizaram o levantamento do canteiro, aplicaram uma palestra que tratava desde a construção passando pela manutenção e colheita da horta, em seguida levaram os participantes da oficina até o local onde foi levantado os canteiros e realizaram uma atividade prática, explicando detalhadamente a mistura de adubos, em seguida os idosos semearam e irrigaram o canteiro com o auxilio dos rondonistas. Essa atividade busca contribuir na cultura alimentar com a implantação da horta, despertando o interesse de cultivar como forma de produção de alimento, incorporando alimentação nutritiva, saudável e a preservação ambiental como eixo gerador da prática pedagógica, realizando dessa horta, uma atividade terapêutica ocupacional.

\section{CONCLUSÃO}

O Projeto Rondon configurou-se como uma ação educativa de extensão que possibilita ao universitário e à sociedade em geral serem parceiros de interação e conhecimentos. Constatou-se, portanto, que o universitário evolui quando sua formação está focada em um maior aprendizado de vida e cidadania, dando prioridade ao desenvolvimento dos trabalhos em sua própria comunidade, pois está diante da realidade e da oportunidade de influenciar diretamente no seu desenvolvimento, criando então uma relação de comprometimento, afetividade e integração.

Diante da oportunidade de conscientizar crianças, adultos, idosos, produtores independendo de sua etnia, mostrando a importância de estar saboreando um alimento saudável e nutritivo, criando na escola ou em sua comunidade uma área verde produtiva pela qual, todos se sintam responsáveis, construir a noção de que o equilíbrio do ambiente é fundamental para a sustentação da vida em nosso planeta, é um processo educativo, cultural e científico que, de forma conjunta possibilita a relação transformadora da universidade e sociedade.

O público alvo teve a oportunidade de apreender, repensar e discutir sobre o desenvolvimento de suas atividades e os alunos puderam colocar em prática aquilo que aprendem na universidade através do atendimento a demanda da comunidade do município, ou seja, através da participação no projeto pode-se perceber que o aprendizado da universidade pode ser utilizado como um instrumento valioso na promoção social e no exercício da cidadania. A partir da interação com a comunidade os rondonistas têm a oportunidade de refletirem sobre a sua própria construção enquanto estudantes e futuros profissionais.

"No âmbito da universidade onde as coisas são previsíveis, quando na realidade temos que nos adaptar e lidar com as diversidades, faz de toda essa experiência tornar o Projeto Rondon uma das melhores experiências de minha vida."

\section{(Leonardo Casimiro, rondonista e autor deste trabalho.)}

Acompanhando a evolução deste Projeto nesta linha do tempo, pudemos perceber que o foco do mesmo era a construção de uma sociedade livre, justa e solidária, bem como a necessidade de desenvolvimento, integração nacional e o preparo dos universitários para a cidadania. O Lema "Integrar para 
não entregar" se faz verdadeiro diante da necessidade da erradicação da pobreza e marginalização, redução das desigualdades sociais e regionais e promoção do bem de todos, sem preconceito e discriminação, fato que torna o Projeto Rondon como o maior movimento voluntário do País.

\section{REFERÊNCIAS}

ABRANCHES, Mônica; MELO, Hélia L.; ÁVILA, Luciene L. Extensão Universitária para o desenvolvimento de comunidades: atuação do projeto Rondon Minas.In: IV SEMINÁRIO DE EXTENSÃO UNIVERSITÁRIA: FORMAÇÃO ACADÊMICA E COMPROMISSO SOCIAL, 4, 2009, Belo Horizonte - MG. Disponível em: vhttp://www1.pucminas.br/proex/arquivos/desenvolvimentocomunidades.pdf. Acesso em: 18 fev. 2014.

BARRETO, Luiz Henrique Moura. Projeto Rondon: planejamento, opiniões e motivações: janeiro e fevereiro de 2007. Salvador: Ed. do autor, 2008.

BRASIL. Institucionalização da extensão nas universidades públicas brasileiras: estudo comparativo 1993/2004. Fórum de Pró-Reitores de Extensão das Universidades Públicas Brasileiras. Comissão Permanente de Avaliação da Extensão Universitária. 2a ed. João Pessoa: Editora Universitária da UFPB. Belo Horizonte: Coopmed, 2007. 90p.

MINISTÉRIO DA DEFESA. Projeto Rondon: Planejamento estratégico. http://projetorondon.paginaoficial. com/portal/index/pagina/id/9718/area/C/module/default 